\title{
História Ambiental: o saneamento da cidade do Rio de Janeiro
}

\section{Environmental History: the sanitation in Rio de Janeiro city}

\author{
${ }^{1}$ Marinéa da Silva Figueira Rodrigues \\ ${ }^{2}$ Antonio Carlos de Miranda
}

\section{RESUMO}

O objetivo central deste estudo é analisar o processo histórico do saneamento na cidade do Rio de Janeiro, no final do século XIX, principalmente, nas suas três últimas décadas, com enfoque nos aspectos socioambientais, a partir de fontes acadêmicas contemporâneas e primárias. Acreditamos que através desta perspectiva histórica seja possível discutir, também, de forma atual, os diversos temas interdisciplinares principalmente em educação ambiental. A cidade do Rio de Janeiro, nas últimas décadas do século XIX, passa por graves problemas de habitação, sobretudo com o crescimento populacional, acentuou-se ainda mais o esgotamento de grande parte dos mananciais que abasteciam a cidade. Esse cenário potencializa as doenças epidêmicas e, em contrapartida, cria-se uma medicina urbana. Assim, forma-se um saber 'médico -administrativo' que visava a 'higienização' da cidade e o seu 'embelezamento'. O modelo são as cidades europeias, com a 'limpeza e o arejamento do ar' e, principalmente, com o afastamento da população pobre do centro da cidade. Assim, fundam-se as bases para a normatização e para o controle da sociedade.

Palavras-chave: saneamento; educação ambiental; socioambiental; história ambiental

\begin{abstract}
The purpose of this study is to investigate the historical process of sanitation improvement in the city of Rio de Janeiro, in the late nineteenth century, mainly in its last three decades, with a focus on social environmental aspects, from contemporary and primary academic sources. We believe that through this historical perspective it is possible to discussal so the current form, the various interdisciplinary themes in the environmental education. Rio de Janeiro city, in the last decades of the nineteenth century, undergoes severe housing problems, especially with population growth, deepened further depletion of most fountains that supplied the city. This scenario is seasonable to epidemic diseases and, on the other hand, an urban medicine is created. Thus, they form a knowledge 'medical-administrative' aimed at 'cleaning' of the city and its 'embellishment'. The models are European cities, with the 'cleaning and aeration of the air', and especially with the removal of the poor from the city center. Therefore, the basis for the regulation and control of society are founded.
\end{abstract}

Keywords: sanitation, environmental education, socio environmental; environmental history

\footnotetext{
1 Universidade Severino Sombra

2 Centro Universitário Plínio Leite
} 


\title{
INTRODUÇÃO
}

Esta investigação tem como objetivo central a realização de um estudo sobre o processo histórico do saneamento na cidade do Rio de Janeiro, no final do século XIX. Essa aproximação do ensino de História com a Educação Ambiental nos conduz à reflexão acerca dos problemas socioambientais que estão presente na sociedade atual, como afirmam Laborde et al. (2007). Por sua vez, "a apropriação dos recursos da natureza e a valoração das paisagens, nesse sentido, possuem uma clara historicidade”, como garante Pádua (2010). Nessa linha, podemos situar essa investigação no campo de estudo da História Ambiental. Aqui cabe um breve parêntese para lembrar que a História Ambiental representa uma área interdisciplinar que surge, principalmente, a partir da década de 1970, junto com os principais congressos ambientais desta época. Em 1974, a revista Annales apresenta como tema 'Histoire et Environnement', de certo modo, o seu prefácio, irá demarcar este campo de estudo:

\begin{abstract}
A história ambiental reúne os temas mais antigos com os mais recentes da historiografia contemporânea: a evolução das epidemias e do clima, ambos os fatores sendo partes integrantes do ecossistema; a série de calamidades naturais (...) a destruição da natureza, causada pelo crescimento populacional e/ou predadores do hiperconsumo industrial; as mazelas de origem urbana que levam à poluição do ar e da água (WORSTER, 1991, p. 200).
\end{abstract}

Vale assinalar que essa aproximação do ensino de História com a Educação Ambiental não representa, segundo Pádua (2010, p. 85), “a mera constatação de exemplos históricos relativamente distantes, mas sim na possibilidade de sua replicação onde quer que se adotem padrões semelhantes de uso destrutivo da terra”. No entanto, é importante estar atento no reconhecimento de que a preocupação com o meio ambiente é um tema bastante recente e, de acordo com este pesquisador, já poderia estar presente, sendo percebida, ou não, em cada período da trajetória humana associada aos vários padrões culturais de cada época. Nesse quadro, Pádua (2010, p. 96) argumenta que "não se trata, portanto, de projetar categorias ambientais e ecológicas do presente no passado, mas sim de utilizar essas categorias, com o devido cuidado, para pensar a existência de sociedades pretéritas”.

O grande desafio, a partir de uma leitura histórica dessa temática, é pensar e discutir de forma atual os diversos temas interdisciplinares, visando à possibilidade de serem evidenciados especialmente em Educação Ambiental. Entre eles, o processo de urbanização e as reformas urbanas; a concessão de serviço público e seus aspectos 'legais'; a influência do capital estrangeiro; os modelos 'científicos’ de saúde e a sua influência social e política na vida urbana; os processos urbanos e discriminatórios que conduzem ao afastamento para a periferia da população mais pobre; a poluição da Baía de Guanabara; as áreas atendidas pelo serviço público de saneamento e distribuição de água que podem representar um privilégio ou uma discriminação. Na verdade, todo esse cenário irá representar uma injustiça social e ambiental.

É importante lembrar que, a partir de 1870, grandes secas assolaram a cidade do Rio de Janeiro, agravadas pelo aumento populacional e pelos danos ambientais causados às nascentes dos rios, pois as matas e florestas de seu entorno passaram a ser derrubadas, em geral, para atender ao comércio de lenha e carvão, às construções das habitações e à cultura de café que surgia na cidade. Nessa época, a metrópole passava por graves problemas de habitação, sobretudo com o crescimento populacional que teve início, a partir do século XIX. Com a instalação da Corte, em menos de duas décadas, a população duplicou, atingindo cerca de 100 mil habitantes no ano de 1822 e 135 mil em 1840. Esse aumento ampliou-se ainda mais no final do século XIX, pela vinda de grande contingente de imigrantes. Tal fato acarretou sérios problemas de salubridade para a vida da cidade. Além disso, o desenvolvimento do sistema de esgoto, entregue como a concessão à Companhia Inglesa "City Improvements", demonstrava simultaneamente avanços e retrocessos no atendimento à população. Pois grande parte da população permanecia alijada desse serviço, continuando a utilizar o serviço braçal dos escravos.

Cabe esclarecer que a Companhia Inglesa "City Improvements" só atendia as moradias da classe abastada, da aristocracia e de prédios públicos, sobretudo na região central da cidade, enquanto a maior parte da população continuava a jogar os seus dejetos nos rios e na Baía de Guanabara. Na verdade, as condições propícias foram criadas para que o acesso à água passasse a ser um cenário explícito de disputa política (que atravessa o 
século XX). Portanto, esse benefício representou um espaço de privilégio ao chegar às torneiras das residências e, também, de exclusão, ao ser necessário buscá-lo nos chafarizes e nas bicas. Por sua vez, nas últimas décadas do século XIX, acentuou-se ainda mais o esgotamento de grande parte dos mananciais que abasteciam a cidade, fato que ocorreu em razão das constantes devastações em seus mananciais, pela ocupação indevida das nascentes e pela necessidade de mais demanda de água. É evidente que esse processo de degradação trouxe como resultado muitas epidemias. Por outro lado, na época, os conceitos médicos apontavam que diversas doenças eram provocadas pela vida urbana associada ao clima. A partir daí, criou-se uma medicina urbana, formando um saber 'médico-administrativo', em que principalmente os médicos poderiam "opinar sobre os melhores métodos de arejamento das cidades”, como afirma Foucault (2011). Abrem-se longas e largas avenidas, que 'são necessárias para manter a saúde da população’. Isto é, a ‘higienização’ da cidade, com o seu embelezamento tendo como modelo as cidades europeias (Paris, por exemplo). Essas mudanças urbanísticas estavam ancoradas em uma teoria médica hegemônica que postulava que a decomposição de matérias orgânicas, dos pântanos, dos solos, entre outros, gerava a produção de gases ('miasmas') cuja inalação pelo ser humano provocava as doenças. Logo, a partir desse conceito, criou-se uma racionalidade que interviria na cidade do Rio de Janeiro em prol da 'limpeza' do espaço urbano e de sua organização, visando um melhor fluxo de ar, entre outros aspectos, que justificariam, inclusive, a demolição de casas no centro urbano e o afastamento da população mais pobre dessas áreas.

Isso posto, este estudo, representa em seu traçado metodológico uma pesquisa de caráter bibliográfica e documental. A partir de fontes acadêmicas contemporâneas e primárias. Estas, em maioria, publicadas no século XIX, representadas por obras impressas, documentos, relatórios oficiais, artigos de jornal, publicações acadêmicas, entre elas, fundamentalmente, revistas médicas e teses da Faculdade de Medicina do Rio de Janeiro. Nessa etapa, foram consultadas obras e documentos no Arquivo Nacional, na Biblioteca Nacional e na Academia Nacional de Medicina. Vale lembrar que os estudantes da Faculdade de Medicina do Rio de Janeiro, no século XIX, deveriam, no final do curso, defender, em sessão pública, uma tese para obterem o título de doutor em Medicina. Nesta investigação, temos como pressuposto que essas teses e os artigos publicados nas revistas médicas representam os discursos legitimados, ao longo do século XIX, pela ciência médica. Portanto, as escolhemos também como importantes fontes primárias de estudo.

\section{HISTÓRIA AMBIENTAL: O SANEAMENTO E A URBANIZAÇÃO DO RIO DE JANEIRO}

Em 25 de abril de 1857 foi assinado por D. Pedro II um contrato de esgotamento sanitário, "nos limites da área central da cidade”, com John Russel, Vianna de Lima Junior e Edward Gotto. Apoiou-se na Lei nº 884, de $1^{\circ}$ de Outubro de 1856, que estabeleceu o orçamento para 1857:

Art. 17; $\S 2^{\circ}$ Contractar, sobre as bases que forem mais vantajosas, a empresa do serviço da limpeza e esgoto da Cidade do Rio de Janeiro, podendo conceder á respectiva Companhia privilegio exclusivo.

Esse contrato teve como base a Lei $\mathrm{n}^{0} 719$, de 28.09.1853, que não fazia restrições a empresas estrangeiras, leia-se, de capital inglês, para atuarem em concessões de serviços públicos.

Art. 11, §3 ${ }^{\circ}$ Contractar: $1^{\circ}$ Com João Frederico Russell, (nome aportuguesado do inglês: John Frederick Russell), ou com outro qualquer, o serviço da limpeza das casas da cidade do Rio de Janeiro e do esgoto das aguas pluviaes (...) Outrosim poderá o Governo isentar de direitos de importação e exportação os objectos concernentes á empresa (grifo nosso).

Em seguida, o contrato foi transferido ou, como destaca Benchimol (1990), "foi entregue sem hesitações", em maio de 1863, a uma companhia de esgoto de capital inglês: 'The Rio de Janeiro City Improvements CompanyLimited’, criada pela casa bancária Gleenand Mills e presidida pelo inglês Edward Gotto. A empresa passou a ter o monopólio desse serviço por 90 anos. Em 1864, é realizada a obra inaugural, com a presença de D. Pedro II. Na verdade, a estação de tratamento eram tanques de precipitação e os efluentes eram despejados diretamente 
na Baía de Guanabara. Sobre a ‘Companhia City Improvements’, o Engenheiro André Rebouças diz: “convertera a Baía de Guanabara numa imensa cloaca” (1888, p. 49). Na fala de Rebouças fica clara a forma como ele encarava a empresa, vendo-a como uma grande poluidora da Baía de Guanabara. Cabe assinalar, como já foi alertado, que a Companhia Inglesa ‘City Improvements' só atendia algumas moradias da classe abastada, da aristocracia e de prédios públicos, na região central da cidade, enquanto a maior parte da população continuava a jogar os seus dejetos nos rios e na Baía de Guanabara.

Nessa época, a medicina atribuía como as principais causas das doenças: o clima quente (até a própria exposição ao sol), a baixa circulação do ar, a ausência de trovoadas, que poderiam acelerar o 'miasma'. Por exemplo, águas estagnadas provocadas pela baixa topografia de determinadas regiões da cidade do Rio de Janeiro, (cercada por morros, 'impedindo a circulação do ar'), aquecidas pelo calor, ao serem evaporadas gerariam emanações que iriam ‘contaminar o ar’ com o mal cheiro: ‘o miasma’ e, assim, provocar doenças.

Em 1887, o Imperador Pedro II apresenta-se enfermo, o jornal 'O Paiz’ (20/04), do Rio de Janeiro, em um artigo com o título ‘A Moléstia do Imperador' descreve o seu estado de saúde: “mas ainda sem ser médico sabe todo mundo como é grave a repetição desses accessos intermitentes enquanto as condições locaes ou orgânicas favorecem a permanência e atividade do miasma que acaso se introduziu no organismo"(grifo nosso).

Com efeito, teorias de médicos europeus, publicadas na 'Revista Médica Brasileira', defendiam que "Nestes países (de clima quente) o sangue sofre uma alteração que explica a palidez de seus habitantes; os outros líquidos também sofrem mudança na sua íntima composição; aquele fluido torna-se mais pobre em fibrina (FERREIRA, 1999, p. 23). Por sua vez, a 'teoria do miasma' estabelecia que os vapores, eflúvios (provocavam mal cheiro) que se desprendiam de matérias orgânicas e ao serem inalados causavam as doenças. Convém lembrar que os estudos de John Snow $(1855,1988)$, em 1854, já apontavam que as epidemias de 'cólera', em Londres, eram causadas pela água contaminada e não pelo miasma. No entanto, houve resistência aos seus resultados. Somente com os trabalhos de Pasteur, em 1878, quando apresenta à Academia de Ciências de Paris a sua 'teoria dos germes’ e Koch, em 1883, ao isolar o vibrião do coléra, a ‘teoria microbiana’ passará a ser aceita.

É interessante observar que, em 06 de março de 1889, diante de uma epidemia de febre amarela, a Inspetoria Geral de Higiene publica nos jornais, 13 (treze) recomendações aos moradores do Rio de Janeiro, entre elas: "1- Manter toda a regularidade na alimentação e excluir dela o uso de frutas verdes. 2 - Evitar, tanto quanto possível, a exposição prolongada a ação do sol” (GAZETA DE NOTÍ́CIAS, 1889, p. 2).

Em relação a essas recomendações, o escritor e jornalista Raul Pompeia escreve a seguir, ironicamente, uma crônica no jornal:

E deitam proficiência, aconselhando doutoralmente que não se coma fruta verde, nem se apanhe sol. Quando muito, aforçuram-se como beneméritos contra a estalagem da Cabeça de Porco, como se da triquina dessa cabeça impura é que fosse morrendo a cidade toda. Passada a epidemia, acredita-se que o mal acabou porque a cidade perdeu o apetite de frutas verdes e todos compraram guarda-sol e a Cabeça de Porco limpou os coradouros (1982, p. 80).

Por sua vez, as teses da Faculdade de Medicina apontam que a febre amarela que assolava a cidade era provocada pelo 'miasma', mas também pela 'ausência de trovoadas'. Uma delas, do médico Candido Barata Ribeiro com o título: "Quaes as medidas sanitárias que devem ser aconselhadas para impedir o desenvolvimento e propagação da febre anmarella na cidade do Rio de Janeiro?”, em 1877, defendia que o surto que ocorreu, em 1870, foi agravado pelo 'calor abrazador', pelas escavações que "libertava as emanações” e pela ausência de chuvas que tinha como consequência “a falta das trovoadas que em épocas anteriores tanto 'limpavão'o ar”: 
Naquella época erão excepcionaes as circunstancias da cidade do Rio de Janeiro, pois além dos rigores de uma grande secca e de um calor abrazador, a falta das trovoadas que em épocas anteriores tanto limpavão o ar, juntava-se a grande quantidade de emanações que se desprendião das excavações, em consequencia das obras por que estava passando a cidade e de muitos outros depositos de matérias orgânicas animaes e vegetaes por toda a parte disseminados (RIBEIRO, 1877, p. 44).

O artigo 'Lições de clinica a febre amarella feitas na Faculdade de Medicina do Rio de Janeiro pelo Dr. João Vicente Torres Homem' publicado na Revista Médica (1873) esclarece porque antes de 1850 não ocorria a febre amarela no Rio de Janeiro. "Para elle o facto se explica pela ausência das trovoadas e chuvas, que eram comuns nesta cidade, impediam a gênese e o desenvolvimento do miasma particular que produz a moléstia".

Outra possibilidade era defendida pela tese "Do actual systema de esgotos da cidade do Rio de Janeiro $e$ de sua influencia sobre a salubridade publica”, em 1875, por João Pires Farinha Filho. Nesse caso, o 'miasma' poderia também ser 'importado’ pelos navios que vinham da América do Norte.

\begin{abstract}
Realmente foi depois que estreitamos nossas relações com a América do Norte que semelhante flagelo começou a apparecer quase todos os annos entre nós. E não é de admirar que importemos deste modo o miasma especifico da febre amarella [...] São estas e outras inexactidões que, durante muito tempo, afastarão a emigração, que, para prosperidade do Brazil, tem augmentado consideravelmente nestes últimos annos. Trate a Camara Municipal do asseio da cidade. Haja, o mais breve possível, o abastecimento d'agua (FARINHA FILHO, 1875, p. 47).
\end{abstract}

Identificamos, entre essas teses, a defesa da 'Companhia City Improvements' dos ataques, (principalmente dos jornais), que a responsabilizavam pelo aumento da febre amarela, em razão das obras necessárias à colocação dos canos, por causa da movimentação de terras.

Para combatermos as imputações daquelles que dizem que a febre amarela tornou-se endêmica entre nós depois da creação da 'Companhia City Improvements', temos a opinião do muito ilustrado Sr. Conselheiro Dr. José Martins da Cruz Jobim, antigo Professor e Director desta Faculdade,[...] dizendo que, si quando a cidade estava em peiores condições hygienicas do que agora, não éramos tão frequentemente visitados pelo typhoicteróide, era porque não estávamos, como hoje, em communicação tão directa com os portos inficionados (FARINHA FILHO, 1875, p. 46) (grifo nosso).

Cabe esclarecer que o médico brasileiro José Martins da Cruz Jobim (1808-1878), citado acima por Farinha Filho, graduou-se pela universidade de Paris, em 1828, influenciado pelas teorias de médicos europeus ele as explicita em artigo na Revista Médica Brasileira (1841, p. 351). "Nestes países (em razão do clima quente) o sangue sofre uma alteração (...) vem a lentidão e languidez em que caem os habitantes desses climas, que sendo por isso incapazes de um trabalho regular” (FERREIRA, 1999, p. 23).

Por sua vez, no jornal ‘O Paiz’ (19/04/1884), o médico Hilário Figueira, no artigo “Succintas considerações sobre o 'Tratamento Racional' das febres palustres”, descreve a maior atividade das emanações do miasma no calor do verão, percebe-se que ele atribui ao miasma também uma série de doenças:

\footnotetext{
durante os grandes calores do verão (...) singularmente insidioso, porque de ordinário, impressiona pouco desagradavelmente o olfato da vítima incauta; tendo observado neste lapso de tempo curiosos e dysenterias, febres intermitentes e remitentes, nevralgias diversas e sobretudo odontalgias, náuseas, vômitos, etc (O PAIZ, 1884, p. 1).
}

Os exemplos acima podem ser classificados como ‘causas naturais’ das doenças: região pantanosa, calor, impedimento do movimento do ar em razão de montanhas, falta de trovoadas, que contribuíam para a presença do miasma. Nesse caso, o meio ambiente passa a ser o indutor das doenças. No entanto, como afirma Ferreira (1999, pag. 6), a literatura médica apontava também para as 'causas não naturais': "também teriam igual importância, sendo por isso necessário proceder-se ao 'exame das coisas chamadas não naturais”. Entre as 'coisas não naturais’: "se atribuía ao grave quadro sanitário do Rio de Janeiro, destacavam-se as que se relacionavam 
com a desordem urbana”. Como 'causa natural', o miasma era um conceito acadêmico que estava presente na maioria dos manuais médicos europeus (em cujas universidades um grande número de médicos e professores da faculdade de medicina do Rio de Janeiro se graduou).

Cumpre lembrar que diversos trabalhos estabeleceram as bases teóricas para essas teorias. Convém destacar, entre eles, os estudos estatísticos que André Guerry (1802-1866) realiza em 1829. De um lado, analisa as admissões hospitalares e a mortalidade devido às várias infecções, principalmente, no Hospital Central de Paris, do outro, compara esses dados, mês a mês, com as condições do clima na cidade de Paris. Isto é, a temperatura, os dias de chuva, de neve, de nevoeiro, de sol, buscando correlacioná-los com as causas de internações hospitalares, com nascimentos, mortes, casamentos e até mesmo suicídios. Em seus estudos, acredita que também há correlações nas mudanças na direção do vento de acordo com os meses do ano e os nascimentos e mortes em Paris (FRIENDLY, 2007).

\section{AS BASES PARA A ORGANIZAÇÃO SOCIAL, PARA A SUA NORMATIZAÇÃO E PARA O CONTROLE DA SOCIEDADE}

Para Foucault (2012), nessa época, coloca-se a seguinte questão: o ar ao ser considerado um dos fatores patogênicos, de que maneira seria possível melhorar a sua qualidade, torná-lo mais sadio, se havia impedimentos urbanos (casas, muros, recintos) à sua circulação? Mudanças urbanas é a resposta. Abrem-se longas e largas avenidas, que são necessárias para manter a saúde da população, por exemplo. Com isso, cria-se uma medicina urbana, em que principalmente médicos irão "opinar sobre os melhores métodos de arejamento das cidades". Portanto, a medicina urbana, como afirma Foucault (2012, p. 162), "não é verdadeiramente uma medicina dos homens, corpos e organismos, mas uma medicina das coisas: ar, água, decomposições, fermentos, uma medicina das condições de vida e do meio de existência”.

Para 'curar' o Rio de Janeiro, a literatura médica do século XIX, indicava medidas terapêuticas visando organizar e ventilar a cidade, dentre as quais, "o dessecamento dos lugares alagadiços, a eliminação de alguns morros que impediam a livre circulação dos ventos e a reformulação da forma de construção das casas, que deveriam ser mais altas e ventiladas” (FERREIRA, 1999, p. 7). Para isso, tornou-se fundamental a demolição de casas e a remoção de moradores. Acrescente, ainda, o controle do fluxo e a aglomeração de pessoas, principalmente, na área central. Em suma, o objetivo era padronizar os costumes e os hábitos da população tendo como norma o modelo burguês das cidades europeias. Portanto, esses conceitos médicos construídos, a partir de meados do século XIX, tiveram como principal consequência 'orientar' a compreensão do funcionamento das sociedades, em relação à urbanização e justificar cientificamente suas intervenções, visando 'curar’ a sociedade das suas patologias, colocando-a, assim, em plena expansão a fim de torná-la 'normal e sadia'. Esses conceitos representam as bases do modelo Higienista.

De acordo com Siqueira (1989, p. 53), no lançamento dos Annales d'Higiene Publique (1829), uma das mais importantes revistas médicas, está o núcleo do ideário que irá marcar profundamente esse modelo: “A Higiene Pública é a arte de conservar a saúde dos homens reunidos em sociedade, e que é chamada a gozar de um grande desenvolvimento e a fornecer numerosas aplicações ao aperfeiçoamento das nossas instituições”. Para esta pesquisadora, tal cenário favoreceu o deslocamento da medicina aproximando-a de forma mais íntima da sociedade, permitindo que se apresentasse não apenas como uma arte de curar doenças, mas, como uma tecnologia de controle social, guardiã do físico e do moral. Essas recomendações estão em sintonia com o texto do Decreto n. 8387 de 19 de Janeiro de 1882, que estabelece, no artigo 16, as atribuições da Inspetoria Geral de Higiene. Nelas, é possível perceber as bases do ideário do controle e da organização social: 
Investigar e indicar todas as providencias necessarias para melhorar as condições hygienicas da cidade no tocante a limpeza, esgotos, irrigação, deseccamento de pantanos, abastecimento d'agua. Ter sob sua vigilancia os estabelecimentos publicos e particulares que requerem cuidados especiaes, como sejam: prisões, quarteis, arsenaes, officinas, theatros, collegios, asylos, hospitaes, casas de saude, de maternidade e de banhos, hoteis e estalagens (quaesquer que sejam suas disposições e denominação), dormitórios publicos e em geral todos os estabelecimentos onde houver agglomeração de individuos; inspeccionar as casas em que viverem reunidas mulheres publicas; e propôr todas as medidas que com relação a taes casas e estabelecimentos reclamar a hygiene publica (DECRETO n. 8387, 1882).

Esse controle aproxima-se com maior intimidade do cotidiano do morador. Na revista 'Annaes da Academia de Medicina' (1886, p. 22) é publicado o discurso do presidente da Academia Imperial de Medicina, o médico Agostinho José de Souza Lima, que indaga acerca das dificuldades da administração sanitária. E responde: "São os que emanam dos mãos habitos, vicios e até simples estupidos caprichos dessa collectividade rebelde chamada povo, tão difficil de se accommodar com os mais insignificantes sacrificios”.

Para ilustrar, lembremos que em razão da epidemia de febre amarela que assolava a cidade do Rio de Janeiro, a Inspetoria Geral de Higiene publica no Jornal Gazeta de Notícias, (06/03/1889, p. 9), recomendações aos moradores, entre elas: "Manter todos os cuidados de acceio corporal, com o uso de banhos geraes e com a substituição frequente das roupas em contacto com o corpo. Evitar o agglomeração de pessoas nos aposentos de dormir (...) que se dê o renovamento continuo do ar nos domicílios”. Enquanto na revista 'Annaes da Academia de Medicina' (1887, p.104), em 'Parecer sobre um Projecto de Saneamento das Habitações', o relator, o médico Soeiro Guarany, comenta acerca do espaço urbano e da moradia, em particular: "É que a historia da casa confunde-se com a da civilização material do Estado; ou, para melhor dizer é a cidade edificada o attestado perpetuo que transmitte ás gerações futuras o progresso physico, moral, intellectual, scientifico de um povo".

Para Foucault (2012, p. 163), “salubridade e insalubridade são o estado das coisas e do meio enquanto afetam a saúde; a higiene pública - no século XIX, a noção essencial da medicina francesa - é o controle político-científico do meio”. Nesse sentido, as reformas urbanas no Rio de Janeiro no final do século XIX e início do século XX, visavam a 'higienização' da cidade, e o seu embelezamento. Como modelo as cidades europeias, com a 'limpeza e o arejamento do ar' e, principalmente, com o afastamento da população mais pobre do centro da cidade. Foucault (2011, p. 368) destaca anda que "O médico se instala nas diferentes instâncias de poder. A administração serve de ponto de apoio e por vezes de ponto de partida às grandes investigações médicas sobre a saúde das populações”. Criam-se as bases para a organização social, para a sua normatização e para o controle da sociedade. A medicina, portanto, conquista um espaço político, já que a ela é atribuída à competência técnica, científica, intelectual e moral para exercer esta função: 'a medicina urbana'. Como diz Foucault; "uma medicina das condições de vida e do meio de existência”.

\section{HISTÓRIA AMBIENTAL: UMA ESTRATÉGIA DE ENSINO APRENDIZAGEM EM EDUCA- ÇÃO AMBIENTAL}

Retomando a questão inicial, como vimos, a História Ambiental é um campo de estudo que surge, principalmente, a partir da década de 1970, juntamente com os principais congressos ambientais desta época. Além disso, como já foi citado, permite trazer para o momento atual os diversos temas interdisciplinares associados ao meio ambiente, visando à possibilidade de serem evidenciados, em sala de aula, especialmente em Educação Ambiental. É necessário salientar que o ser humano está imerso em visões sociais e historicamente construídas com padrões culturais de cada época. Todavia, o modo de produção vai efetivamente balizar essa visão de mundo e, por certo, de forma profunda a sua percepção e a sua ação em relação ao meio ambiente.

Convém assinalar também, como afirmam Pádua \& Martinez (2011, p. 2), “o potencial dinamizador que a História Ambiental pode desempenhar no ensino de História nos níveis fundamental, médio e superior, em atendimento das proposições dos PCNs, e na organização das estratégias para a Educação Ambiental no Brasil”. 
Entre essas estratégias, a nosso ver, situa-se o tema central deste artigo que representa a história do processo de urbanização e as diversas reformas urbanas da cidade do Rio de Janeiro, com o foco nas contradições e nas iniquidades socioambientais presentes neste processo.

Já alertamos que esses processos urbanos com frequência são discriminatórios, pois afastam das áreas nobres ou mais valorizadas da cidade a população mais pobre, conduzindo-a para a periferia, ou obrigando-a a viver nas encostas dos morros ou nas margens dos rios, agravando as suas próprias condições de saneamento e reduzindo a drenagem das águas das chuvas. Portanto, essas pessoas serão as vítimas também das enchentes e dos deslizamentos. Na verdade, todo esse processo representa uma injustiça social e ambiental. Nesse sentido, convém lembrar Loureiro et al. (2003, p. 20) quando afirma que;

Como conceito e movimento, justiça ambiental constitui-se em vetor importante de contestação ao modelo de desenvolvimento vigente, de explicitação da vinculação entre justiça social e ambiental e de luta pela organização popular para exigir políticas públicas inclusivas e democráticas.

Para ilustrar, no período 1962-1974, no município do Rio de Janeiro, foram removidos para áreas afastadas 139.218 moradores, representando 26.193 casas (VALLADARES, 1980). Essas remoções foram para áreas, muitas vezes, esquecidas do poder público, sem o adequado saneamento, distribuição de água, urbanização, transporte, postos de saúde, escolas e lazer. Na verdade, a remoção afasta principalmente o morador do local de seu trabalho, do seu sustento. Associado a um transporte público precário, traz como consequência um longo tempo em deslocamento, com isso, reduz-se a qualidade de vida desse morador, a sua capacidade de trabalho e de estudo, o lazer e o descanso. Na origem dessa precariedade de transporte público em nossos dias estão os aspectos 'legais' (e de lucro) de licitações de concessões de serviços públicos, que criam mecanismos para não atender (no mínimo, de forma eficiente) a essa população. Em contraste, os moradores de áreas mais nobres possuem os melhores serviços públicos. Tal fato propicia e potencializa a criação de espaços e de áreas influenciadas pela especulação imobiliária. Com isso, agrava-se a dificuldade de moradia dessa parcela da população, que agora será efetivamente forçada a buscá-la em bairros da periferia. Além disso, cada vez mais se afastando do centro ou de locais onde são oferecidas as oportunidades de empregos. Portanto, reproduz-se o histórico privilégio na concessão de serviços públicos citado nesse estudo, seja pela remoção de moradores ou por mecanismos especulativos. Revela-se, portanto, como afirmam Loureiro \& Layrargues (2013, p. 63) os "mecanismos de desigualdade socioambiental que concentram os processos decisórios e privatizam os bens públicos, tornando possível e legítimo a utilização dos bens coletivos e naturais para interesses privados”. Já a influência do capital inglês, no século XIX (e início do século XX), como sabemos, dará lugar ao capital transnacional, com generosos privilégios em concessões de serviços públicos. Enquanto que a poluição da Baía de Guanabara, já apontada desde o final do século XIX, atualmente, agravou-se ainda mais. Segundo o INEA, estima-se que 350 toneladas/ dia de esgoto sejam despejados e $70 \%$ ainda não é tratado.

Portanto, o estudo da História Ambiental permite trazer à tona uma análise da gênese das mazelas socioambientais e de seus mecanismos discriminatórios. Assim, retira o véu e coloca luz nesses mecanismos e dinamiza a sua discussão em Educação Ambiental. Nessa linha, convém lembrar as palavras de Mészaros (2005, p. 95) ao destacar o poder de um sistema do capital globalmente dominante e totalitário que submete:

cegamente aos mesmos imperativos a questão da saúde e a do comércio; a educação e a agricultura; arte e a indústria manufatureira, que se sobrepõe a tudo seus próprios critérios de viabilidade, desde as menores unidades de seu microcosmo até as maiores empresas transnacionais, desde as mais íntimas relações pessoais aos mais complexos processos de tomadas de decisão dos vastos conglomerados industriais, sempre a favor dos fortes contra os fracos.

Embora em períodos diferentes, como afirmam Ferreira \& Miranda (2012, p. 105), “a história é reproduzida, assim, o ambiente é mais que estrutura arquitetônica, é reconhecer as relações da existência humana em seu espaço”. Portanto, nos dias atuais, confirmam-se os mecanismos discriminatórios que fazem com que as áreas atendidas pelo serviço público representem um privilégio ou uma discriminação. 


\section{CONSIDERAÇÕES FINAIS}

A partir de meados do século XIX, ocorre a expansão do tecido urbano da cidade do Rio de Janeiro, transformando-a em uma grande metrópole. Os problemas urbanos gerados por essa transformação e pela pressão demográfica fomentada pelos interesses capitalistas geraram danos ambientais, entre outros, nas nascentes dos rios que abasteciam a cidade e a contaminação da baía de Guanabara, uma vez que o esgoto era transportado pelos tigres, em barricas e jogado no litoral. Já com a concessão à companhia inglesa 'City Improvements', o esgoto passou a ser canalizado, mas somente servindo a uma pequena região central da cidade, prédios públicos, igrejas e a moradores que representavam uma elite social. Por sua vez, o esgoto canalizado era encaminhado também para a Baía de Guanabara sem nenhum tratamento, ampliando o processo de poluição de suas águas.

Além disso, o acesso à água passa a ser indispensável para o consumo da população e para o saneamento, pois a sua falta significava, por exemplo, não lavar as ruas e os encanamentos de esgoto. O acesso a esses serviços passa a ser explicitamente um cenário de disputa política (que atravessa o século XX). Representa um espaço de privilégio chegar às residências e, também, de exclusão, para a maioria da população. Fundam-se as bases para a normatização, para o controle da sociedade e para a injustiça social.

Por fim, ficou claro que a História Ambiental pode se transformar em uma importante estratégia de discussão de temas interdisciplinares envolvendo, entre outros, a História, a Educação Ambiental, o espaço urbano, a saúde pública e os problemas socioambientais que se apresentam e desafiam à sociedade atual.

\section{REFERÊNCIAS}

ABREU, Maurício de Almeida. Evolução urbana do Rio de Janeiro. Rio de Janeiro: Jorge Zahar, 2006.

AZEREDO, M., MOTTA, A., GELMAN, M. Saneamento: Principais acontecimentos da História do Saneamento no Município do Rio de Janeiro. Revista Internacional do Conhecimento, ano 3, n. 5, 2012.

BENCHIMOL, Jaime Larry. Pereira Passos: um Haussmam tropical; a renovação urbana da cidade do Rio de Janeiro no início do século XX. Rio de Janeiro: Coleção Biblioteca Carioca, vol.11,1990.

BRASIL. Decreto $\mathbf{n}^{\mathbf{0}} \mathbf{8 3 8 7}$ de 19 /01/1882. Attendendo a urgente necessidade de melhorar o serviço da saúde publica. Disponível em: <http://www.lexml.gov.br/urn/urn:lex:br:federal:decreto:1882-01-19;8387>. Acesso em: 27/03/2013.

BRASIL. Lei $\mathbf{n}^{\mathbf{0}}$ 719, de 28 de Setembro de 1853. Fixando a Despeza e orçando a Receita para o exercício de 1854-1855. Disponível em: <http://www2.camara.leg.br/legin/fed/lei/1824-1899/lei-719-28-setembro-1853558713-publicacaooriginal-80217-pl.html>. Acesso em: 05/03/2013.

BRASIL. Lei $\mathbf{n}^{\mathbf{0}} \mathbf{8 8 4}$, de $1^{\mathbf{0}}$ de Outubro de 1856. Fixando a Despeza e orçando a Receita para o exercicio de 1857-1858. Disponível em: http://www2.camara.leg.br/legin/fed/lei/1824-1899/lei-884-1-outubro-1856571087-publicacaooriginal-94177-pl.html.>. Acesso em: 05/03/2013.

FARINHA FILHO, João Pires. Do actual systema de esgotos da cidade do Rio de Janeiro e de sua influencia sobre a salubridade publica. Tese de Doutorado. Faculdade de Medicina, Rio de Janeiro,1875.

FERREIRA, L. O. Os periódicos médicos e a invenção de uma agenda sanitária para o Brasil (1827-43). História, Ciências, Saúde — Manguinhos, VI (2): 331-51, jul.-out. 1999.

FERREIRA, Nilzete; MIRANDA, Antonio Carlos de. Uma Passagem no Tempo: do cortiço à favela contemporânea. Corpus et Scientia. v. 8, n. 2, 99-108, 2012. 
FIGUEIRA,Hilário. Succintas considerações sobre o 'Tratamento Racional’ das febres palustres. O Paiz, p. $1,19 / 04 / 1884$.

FOUCAULT, Michel. Arte, Epistemologia, Filosofia e História da Medicina. Rio de Janeiro: Editora Forense, 2011. Michel. Microfísica do Poder. São Paulo: Edições Graal, 2012.

FRIENDLY, Michael. Guerry’s Moral Statistics of France: Challenges for Multivariable Spatial Analysis. Statistical Science. vol. 22, no. 3, 368-399, 2007.

GAZETA DE NOTÍCIAS. Recomendações da Inspetoria Geral de Higiene. RJ, p. 9, 06/03/1889.

GUARANY, Soeiro. Parecer sobre um Projecto de Saneamento das Habitações. Annaes da Academia de Medicina.v.1, p. 104, 1887.

LABORDE, André; SILVA, Cassiano; SOLDERA, Lisiane. Ensino de História e Educação Ambiental: pensando em temas transversais para a formação de educadores. Revista Virtu, UFJF, v.2, 2007.

LIMA, Agostinho José de Souza. Discurso do presidente da Academia Imperial de Medicina. Annaes da Academia de Medicina, n.1, p. 22, 1886.

LOUREIRO, Carlos F.; AZAZIEL, M.; FRANCA, Nahyda. Educação Ambiental e gestão participativa em Unidades de Conservação. Rio de janeiro: Ibase, 2003.

LOUREIRO, Carlos F.; LAYRARGUES, Philippe. Ecologia política, justiça e educação ambiental crítica:perspectivas de aliança contra-hegemônica. Trab. educ. saúde vol.11 n.1 Rio de Janeiro Jan. 2013.

MÉSZAROS, István. A educação para além do capital. São Paulo: Boitempo, 2005.

O PAIZ. A Moléstia do Imperador. RJ, p. 2, 20/04/1887.

PÁDUA, José Augusto. As bases teóricas da história ambiental. Estudos Avançados.vol.24 no. 68, São Paulo, 2010.

PÁDUA, Jóse Augusto. MARTINEZ, Paulo. História Ambiental: discussões teóricas e pesquisas empíricas. XXVI Simpósio Nacional de História. USP. p. 2, 2011. Disponível em: <http://www.snh2011.anpuh.org/>. Acesso em: 20/03/2013.

POMPÉIA, Raul. Crônica do Rio. Rio de Janeiro: MEC/Civilização Brasileira, 1982.

REBOUÇAS, André Pinto. Esgoto do Rio de Janeiro. Revista de Engenharia, p.49, 1888.

Diário e notas autobiográficas: texto escolhido e anotações por Ana Flora e Inácio José Veríssimo. Rio de Janeiro: J. Olympio, 1938.

3RIBEIRO, Candido Barata, Quaes as medidas sanitárias que devem ser aconselhadas para impedir o desenvolvimento e propagação da febre anmarella na cidade do Rio de Janeiro? Tese de Doutorado. Faculdade de Medicina, Rio de Janeiro, 1877.

SNOW, John. El Colera Acerca de Golden Square, 1854. In: El desafio de la epidemiologia. Publ. Cient. 505, Washington, 1988.

On the mode of communication of cholera, London: John Churchil, second edition, 1855. Disponível em: <http://books.google.com.br/books?hl=pt>. Acesso em: 15/09/2012. 
SIQUeIRA, Marcia Terezinha Dalledone. Saúde e Doença na Província do Paraná.Tesede Doutorado. Curitiba: UFPR, 1989.

TORRES HOMEM, João Vicente. Lições de clinica a febre amarella feitas na Faculdade de Medicina do Rio de Janeiro. Revista Médica, edição 16, p. 218, 1873.

VALLADARES, Lícia. Passa-se uma casa: uma análise do programa de remoção de favelas do Rio de Janeiro. Rio de Janeiro: Zahar, 1980.

WORSTER, D. Para fazer história ambiental. Estudos Históricos, v.4, n.8, p.198-215, 1991. 